\title{
Investigation of the biosynthesis of the pipecolate moiety of neuroprotective polyketide meridamycin
}

\begin{abstract}
Hao Jiang ${ }^{1,3}$, Bradley Haltli ${ }^{2,4}$, Xidong Feng ${ }^{2}$, Ping Cai ${ }^{1}$, Mia Summers ${ }^{2}$, Jason Lotvin ${ }^{1}$ and Min $\mathrm{He}^{2,5}$
Biogenesis of the pipecolate moiety of neuroprotective agent meridamycin in Streptomyces sp. NRRL30748 was investigated in feeding studies using lysine specifically labeled with ${ }^{15} \mathrm{~N}$ at the $\alpha$-amino or the $\varepsilon$-amino nitrogen position. Fourier transform mass spectrometry analysis with ultra-high mass resolving power and accurate mass measurement capability was employed to resolve the ${ }^{15} \mathrm{~N}$ peak of labeled meridamycin from the ${ }^{13} \mathrm{C}$ peak of unlabeled meridamycin, allowing the precise calculation of labeling contents under each condition. The relative enrichment of ${ }^{15} \mathrm{~N}$-labeled meridamycin was $\sim 43 \%$ with $\mathrm{L}-\left[\alpha-{ }^{15} \mathrm{~N}\right]-$-lysine feeding and $\sim 14 \%$ with $\mathrm{L}_{-}\left[\varepsilon^{-}{ }^{15} \mathrm{~N}\right]$-lysine feeding, suggesting two distinguishable pathways, with concomitant loss of either the $\varepsilon$-amino group or the $\alpha$-amino group of lysine, were involved in the generation of the pipecolate moiety of meridamycin in this bacterium. PCR cloning using degenerate primers identified a proC gene encoding a putative pyrroline-5-carboxylate reductase, which was expected to catalyze the conversion of piperideine-6-carboxylate to pipecolate. However, inactivation of this locus did not significantly affect the incorporation of $\alpha^{-15} \mathrm{~N}$ - or $\varepsilon^{-15} \mathrm{~N}$-labeled lysine into meridamycin, indicating the existence of an alternative route for the last step of the lysine $\varepsilon$-transamination pathway. This work revealed the diversity and complexity of the biosynthetic pathways for pipecolate synthesis in the meridamycin producing bacterium Streptomyces sp. NRRL30748.
\end{abstract}

The Journal of Antibiotics (2011) 64, 533-538; doi:10.1038/ja.2011.45; published online 25 May 2011

Keywords: FTMS; isotope feeding; meridamycin; pipecolate

\section{INTRODUCTION}

Meridamycin and its naturally occurred analog normeridamycin are non-immunosuppressive macrocyclic polyketides with potent neuroprotective activity in dopaminergic neurons. ${ }^{1}$ A so-called 'FKBP12binding motif', which is composed of a pipecolate ester and a cyclic hemiketal moiety, is shared by meridamycin and the structurally related immunosuppressant rapamycin and FK506/FK520. This structural motif is indispensable for the biological activity of rapamycin and FK506/520 due to its involvement in the binding of their initial in vivo target, FKBP12. ${ }^{2}$ However, normeridamycin, which differs from meridamycin by the replacement of the pipecolate moiety with proline, still exhibits potent neuroprotective activity despite reduced FKBP12-binding affinity, suggesting the mode of action of these two compounds likely involves an initial target other than FKBP12. ${ }^{1}$ Normeridamycin is co-produced with meridamycin under various fermentation conditions. Understanding the biosynthetic route of pipecolate would facilitate the rational design of experiments to selectively produce one of these two neuroprotective compounds, as well as to serve as the first step toward generating novel analogs with other amino acids incorporated at this position for more structureactivity relationship studies.
Pipecolic acid is widely distributed in plants, animals and microorganisms as an important precursor of many useful natural products. Multiple routes have been documented for the biosynthesis of this non-proteinogenic amino acid. ${ }^{3,4}$ In summary, two general pathways have been established for converting lysine into pipecolic acid, distinguishable by the loss of a specific amino group of lysine. One route is through the loss of the $\alpha$-amino group of lysine to form $\Delta^{1}$-piperideine-2-carboxylate (P2C) as an intermediate, which is reduced to pipecolic acid with the incorporation of the original $\varepsilon$-nitrogen from L-lysine (Figure 1, path A). The alternative route is via the formation of $\Delta^{1}$-piperideine-6-carboxylate (P6C) intermediate due to the loss of $\varepsilon$-nitrogen, which results in the incorporation of the $\alpha$-nitrogen into pipecolic acid (Figure 1, path B). Previous studies have identified a lysine cyclodeaminase, RapL, to be responsible for the generation of the pipecolate moiety of rapamycin in Streptomyces hygroscopicous by catalyzing the direct cyclodeamination of L-lysine, a process homologous to the conversion of L-ornithine to L-proline catalyzed by ornithine cyclodeaminase. ${ }^{5}$ Biochemical characterization of purified RapL protein has established a redox catalytic process including a reversible oxidation at the $\alpha$-amine, internal cyclization and subsequent reduction of the $\mathrm{P} 2 \mathrm{C}$ intermediate, and confirmed

\footnotetext{
${ }^{1}$ Department of Bioprocess Development, Pfizer, Pearl River, NY, USA and ${ }^{2}$ Department of Chemical Science, Pfizer, Pearl River, NY, USA

${ }^{3}$ Current address: Hongda Industrial Group, Harbin, China.

${ }^{4}$ Current address: University of Prince Edward Island, Charlottetown, Canada PE CIA 4P3.

${ }^{5}$ Current address: Division of Cancer Treatment and Diagnosis, Developmental Therapeutics Program, National Cancer Institute, NIH, Bethesda, MD 20892, USA.

Correspondence: Dr M He, Division of Cancer Treatment and Diagnosis, Developmental Therapeutics Program, National Cancer Institute, NIH, 6130 Executive Blvd.-MSC7458, EPN/RM 8024, Bethesda, MD 20892, USA.

E-mail: hem3@mail.nih.gov

Received 7 February 2011; revised 12 April 2011; accepted 26 April 2011; published online 25 May 2011
} 


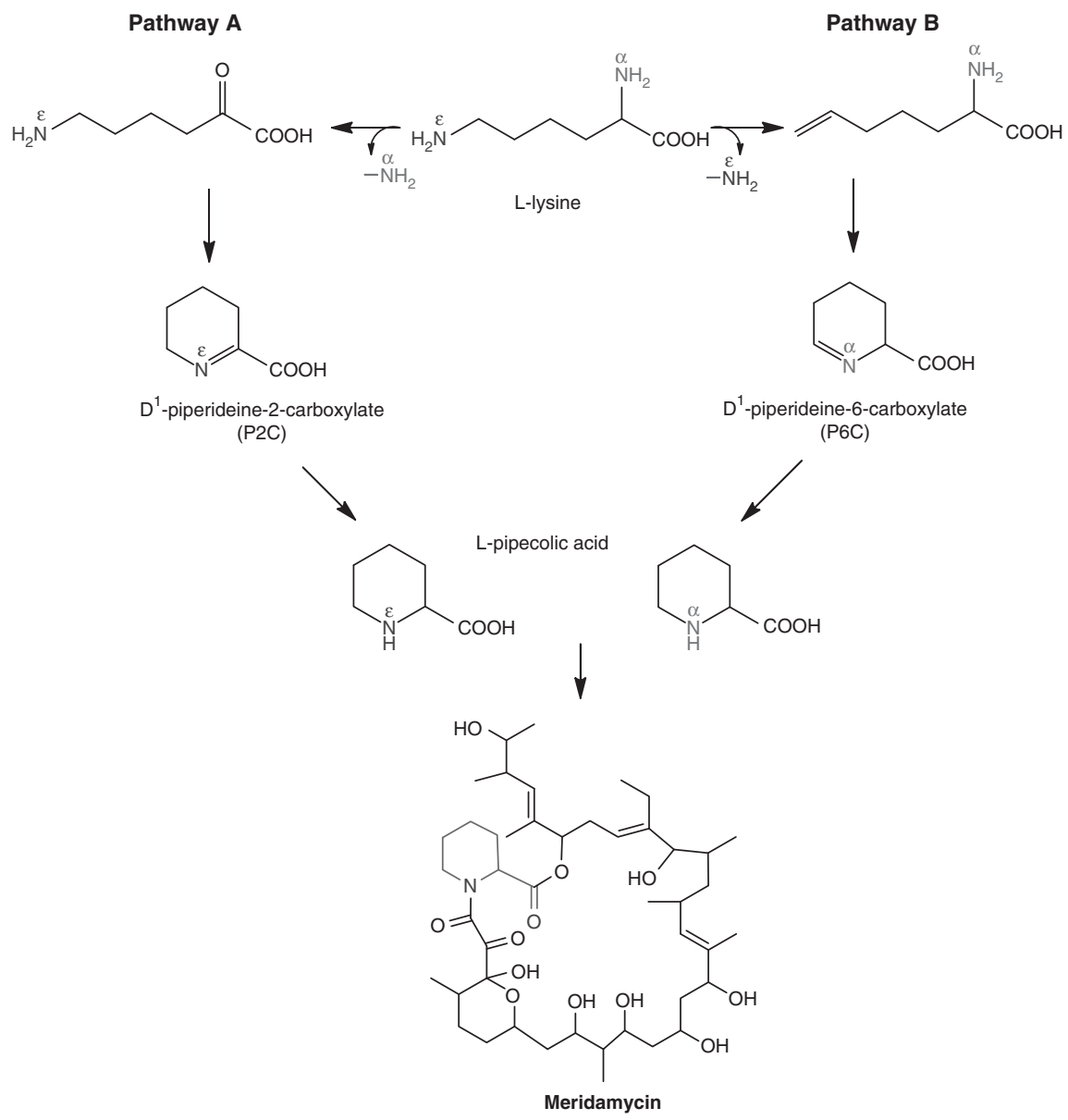

Figure 1 Two biosynthetic pathways from lysine to pipecolic acid and its incorporation into meridamycin.

the cyclodeamination reaction involves the loss of the $\alpha$-amine and the retention of the $\varepsilon$-amine of L-lysine in the L-pipecolate product. $^{6}$ The gene encoding RapL $(r a p L)$ is colocalized with other biosynthetic genes involved in rapamycin biosynthesis, ${ }^{7}$ and its orthologs are also present in the biosynthetic gene clusters of FK506/520, ${ }^{8,9}$ virginiamycin $S,{ }^{10}$ tubulysin ${ }^{11}$ and friulimicin. ${ }^{12}$ However, a rapL homolog was neither found in the biosynthetic gene cluster of meridamycin of Streptomyces sp. NRRL 30748 nor in the rest of the genome, as indicated by extensive PCR and Southern hybridization analysis. ${ }^{13}$ It was speculated that production of pipecolate in this strain likely involves pathway(s) other than the direct lysine cyclodeamination.

Feeding experiments using ${ }^{15} \mathrm{~N}$-labeled lysine had been previously employed to investigate the biosynthesis of the pipecolate moiety of anthelmintic agent marcfortine, in which FAB-MS coupled with NMR analysis were used to quantify the relative enrichment of ${ }^{15} \mathrm{~N}$ nuclei and to identify the specific loss of the $\alpha$ - or $\varepsilon$-amino group of lysine. ${ }^{14}$ However, applying this approach to investigate the biosynthesis of meridamycin would be challenging, because the production level of meridamycin is low; and thus, it is difficult to prepare pure ${ }^{15} \mathrm{~N}$-labeled material for NMR analysis. Also, both the ${ }^{15} \mathrm{~N}$-labeled meridamycin and the naturally occurring ${ }^{13} \mathrm{C}$ isotope of unlabeled meridamycin have the same nominal $\mathrm{m} / \mathrm{z} 845$ in the mass spectrum. Therefore, remarkably high mass resolving power and accurate mass measurement capability would be required to unambiguously identify the ${ }^{15} \mathrm{~N}$ species, particularly when it is low in abundance compared with the naturally present ${ }^{13} \mathrm{C}$ isotope. Recently, Fourier transform ion cyclotron resonance mass spectrometry (FTICR-MS or FTMS) with ultra-high resolution and mass measurement accuracy (p.p.m.) capabilities has demonstrated its great utility in studying stable isotopelabeled natural products. ${ }^{15,16}$ The isotopic fine structures (consisted of a group of isobaric species with a difference in mass of only a few $\mathrm{mDa}$ ) complicated by the isotopic enrichment normally present in natural metabolites, could be revealed by FTMS to the extent that the ${ }^{15} \mathrm{~N}$-labeled peak can be resolved from the naturally occurring isobaric ${ }^{13} \mathrm{C}$ peak. The p.p.m. mass measurement accuracy on all the resolved peaks enables unequivocal peak identification and direct calculation of the labeling extent, thus has greatly facilitated the interpretation of the underlying chemistry of biosynthetic processes.

Herein, we report the use of feeding experiment with isotopically labeled precursors coupled with FTMS analysis to investigate the biogenesis of the pipecolate moiety of meridamycin in Streptomyces sp. NRRL30748, and the cloning and characterization of a gene encoding pyrroline-5-carboxylate (P5C) reductase which was expected to be involved in the last step of the lysine $\varepsilon$-deamination pathway.

\section{MATERIALS AND METHODS}

Bacterial strains, culture conditions, reagents and media Streptomyces strains were grown at $26^{\circ} \mathrm{C}$ in WSB4YESS medium $(0.5 \%$ WGE $80 \mathrm{M}, 1.5 \%$ SE50MAF, $0.3 \%$ yeast extract, $2 \%$ soluble starch, $2 \%$ glucose, $\mathrm{pH} 7.0)$ for 3 days with shaking at 250 r.p.m. In all, $0.5 \mathrm{ml}$ of the above seed culture was inoculated into $25 \mathrm{ml}$ of fermentation medium (6\% Maltrin M180, $1 \%$ Nutrisoy soyflour, $0.6 \%$ Difco yeast extract, $0.1 \% \mathrm{CaCO}_{3}, 2 \%$ glucose, $\mathrm{pH}$ 7.0). Fermentation flasks were shaken at 250 r.p.m. for 7 days. For labeling experiments, L-[3,3,4,4,5,5,6,6- $\left.\mathrm{D}_{8}\right]$-lysine (2 or $4 \mathrm{~mm}$ final concentration) or 
${ }^{15} \mathrm{~N}$-labeled lysines (25 mm final concentration) (Cambridge Isotope Laboratories) were added after $24 \mathrm{~h}$ of fermentation at $26^{\circ} \mathrm{C}$. Escherichia coli strains were grown in Luria-Bertani (LB) medium supplemented with either apramycin $\left(50 \mu \mathrm{g} \mathrm{ml}^{-1}\right)$ or ampicillin $\left(100 \mu \mathrm{g} \mathrm{ml}^{-1}\right)$. KOD Hot start DNA polymerase (Novagen, San Diego, CA, USA) was used for PCR amplification following the manufacturer's instructions. Genomic DNA of streptomycetes was isolated using the procedure described previously. ${ }^{13}$ Plasmid DNA was isolated using the Zyppy plasmid mini-prep kit (Zymo Research, Orange, CA, USA). Transformation of the plasmids into E. coli was performed using either NovaBlue competent cell or EPI300 electro competent cells. Conjugation experiments were performed as described previously. ${ }^{13}$

\section{Methods of LC-MS analysis}

Fermentation broth $(2 \mathrm{ml})$ was mixed with two volumes of ethyl acetate/methanol (95:5) by vortexing. After centrifugation, an aliquot of supernatant $(250 \mu \mathrm{l})$ was taken and diluted with methanol to a final volume of $1 \mathrm{ml}$ for quantitative analysis. LC-MS was conducted using an Agilent 1100 HPLC coupled with 1100 MSD mass spectrometer (Agilent, Santa Clara, CA, USA). A Zorbax SB C18 column $(3 \times 150 \mathrm{~mm}, 3.5 \mu \mathrm{m}$, Agilent $)$ was used for LC separation. A solvent system containing water with $5 \mathrm{~mm}$ ammonium acetate (A) and $\mathrm{MeOH}(\mathrm{B})$ was used as the mobile phase. The gradient of the mobile phase started from $65 \% \mathrm{~B}$ to $90 \% \mathrm{~B}$ over $15 \mathrm{~min}$ and was held at $90 \% \mathrm{~B}$ for $6 \mathrm{~min}$ before returning to the initial conditions. The flow rate was set at $0.3 \mathrm{ml} \mathrm{min}^{-1}$. Under this condition, meridamycin showed retention time at $12.3 \mathrm{~min}$. For quantitation of meridamycin, the negative electro spray ionization mass spectrum was acquired in single ion monitoring mode. The meridamycin molecular ion at $\mathrm{m} / \mathrm{z} 820.6$ was monitored. The peak areas at $\mathrm{m} / z 820.6$ from the standard meridamycin solutions were measured to generate the linear calibration curve for quantitation of meridamycin in each fermentation sample.

\section{Methods of HPLC-FTMS analysis}

High resolution mass spectra were obtained using a Bruker APEXII FTICR mass spectrometer equipped with an actively shielded 9.4 Tesla superconducting magnet (Magnex Scientific, Varian Inc., Lake Forest, CA, USA), an external Bruker APOLLO ESI (Bruker Corporation, Billerica, MA, USA) source and a Synrad $50 \mathrm{~W} \mathrm{CO}_{2} \mathrm{CW}$ laser. Typically, a 5- $\mu \mathrm{l}$ sample was loaded into the nanoelectrospray tip (New Objective, Woburn, MA, USA) and at least $30 \mathrm{~min}$ continuous ion signal could be maintained. A high voltage about $1000 \mathrm{~V}$ was applied between the nanoelectrospray tip and the capillary to maintain a stable electrospray operation. Each spectrum was the sum of 32 or 64 scans, consisting of one million data points. HPLC-FTMS experiments were employed utilizing an Agilent 1100 HPLC system (Agilent). The sample was injected onto a SymmetryShield $\mathrm{RP}_{18} 3.5 \mu \mathrm{m} 4.6 \times 100 \mathrm{~mm}$ HPLC column using a linear gradient from 65 to $90 \%$ mobile phase $\mathrm{B}(\mathrm{MeOH})$ mixed with mobile phase A (10 $\mathrm{mm}$ ammonium acetate buffer) over $15 \mathrm{~min}$, and then held for $6 \mathrm{~min}$. The flow rate was $0.3 \mathrm{ml} \mathrm{min} \mathrm{m}^{-1}$, and the analytes were directly sampled by the ESI source. A delay between the start of sample injection and data acquisition was set to $5.0 \mathrm{~min}$. For HPLC-FTMS experiment, each spectrum was the sum of eight scans, consisting of 512000 data points. All mass spectra, acquired from either the offline nanoelectrospray FTMS or the online HPLC-FTMS, were externally or internally calibrated using the HP tuning mix (G2421A). Bruker Xmass software (versions 5 and 6) (Bruker Corporation) was used for data acquisition and analysis, including the calculations for predicted masses with corrections for the mass of the electrons responsible for the charge state of the ion. The reported errors $(\Delta)$ are the differences between the experimental and predicted values expressed in $\mathrm{mDa}$. Mass resolving power was defined as the ratio of the ion mass over the mass spectral peak full width at half maximum peak height.

Cloning of proC gene and generation of proC disruption mutant Degenerated PCR primers were designed based on the conserved regions of known bacterial P5C reductases, including P5C reductase from Streptomyces coelicolor A3(2) (accession NC_003888.3) ${ }^{17}$ and Streptomyces avermitilis MA4680 (accession NC 003155.4). ${ }^{18}$ The forward primer (ProC F1b) has the sequence $5^{\prime}-\mathrm{CT}(\mathrm{GC}) \mathrm{AC}(\mathrm{GC}) \mathrm{GT}(\mathrm{GC}) \mathrm{AAGCC}(\mathrm{GC}) \mathrm{CAGG}-3^{\prime}$, and the reverse primer (ProC_R2b) has the sequence $5^{\prime}$-CC(GC)GC(GC)GG(GC)(GC)(AT) (GC)GT(GC)AC-3'. By using this pair of primers and the genomic DNA of Streptomyces sp. NRRL30748 as the template, an $\sim 500$ bp DNA fragment was amplified and fully sequenced, which contains an internal portion of a proC gene homolog. This DNA fragment was used as a probe to screen the previously generated cosmid library of Streptomyces sp. NRRL30748, ${ }^{13}$ leading to the identification of several positive clones. Sequencing of these cosmids with primers designed based on the known sequence of the $\sim 500 \mathrm{bp}$ internal fragment toward the outside flanking ranges had generated a consensus contig of $3305 \mathrm{bp}$, which contains the full-length proC gene. To generate the disruption mutant of this gene, an $\sim 3 \mathrm{~kb}$ DNA fragment containing proC was cloned into pCU19 using primers $5^{\prime}$-CGACCCGCCACCCCCACG- $3^{\prime}$ and $5^{\prime}$-CGGCCGCCCCTTT CCACAC- $3^{\prime}$, and an internal Pfl MI/Dra III of this gene was replaced by an oriT/apr cassette. The resulting construct was introduced into Streptomyces sp. NRRL30748 to generate a proC disruption mutant via double crossover.

\section{RESULTS AND DISCUSSION}

Confirmation of the lysine origin for the pipecolic acid moiety of meridamycin

Before employing ${ }^{15} \mathrm{~N}$-labeled lysine to dissect the biogenesis routes for pipecolate, we first fed fermentation cultures of Streptomyces sp. NRRL30748 with deuterated $\mathrm{L}-\left[3,3,4,4,5,5,6,6-\mathrm{D}_{8}\right]$-lysine to validate the lysine origin of this moiety of meridamycin. LC-MS analysis of the fermentation extract detected the presence of multiple deuterated meridamycins, with incorporation of $6-8$ deuterium atoms. The most abundant species was meridamycin $\left[\mathrm{d}_{8}\right]$ with the expected $\mathrm{m} / \mathrm{z}$ of 828.7 , and its relative enrichment was proportional to the amount of deuterated L-lysine fed into the culture (Table 1). This result clearly demonstrated that the pipecolate moiety of meridamycin was indeed originated from L-lysine.

\section{Characterization of the biogenesis of pipecolate by FTMS}

To monitor the selective loss of amino group in L-lysine, crude extracts of fermentation broths prepared with $\mathrm{L}_{-}\left[\alpha_{-}{ }^{15} \mathrm{~N}\right]-$ or $\mathrm{L}-\left[\varepsilon^{-}{ }^{15} \mathrm{~N}\right]-$ lysine were subjected to FTMS analysis with ultra-high mass resolution power ( $>150000$, FWHM) and accurate mass measurement (p.p.m.) capability. Molecular ions detected in the positive mode nanoelectrospray FTMS obtained for each sample are shown in Figure 1. For the sample obtained from $\mathrm{L}-\left[\alpha_{-}{ }^{15} \mathrm{~N}\right]$-lysine feeding, a molecular ion $\mathrm{m} / \mathrm{z} 844.51772$ was assigned as the sodium adduct molecular ion (monoisotopic) for the unlabeled meridamycin molecule based on accurate mass measurement $\left(\mathrm{C}_{45} \mathrm{H}_{75} \mathrm{NO}_{12} \mathrm{Na}^{+}\right.$, cald $\mathrm{m} / z$ 844.51815, $\Delta=-0.43 \mathrm{mmu}$ ). The remarkable mass resolving power combined with accurate mass measurement led to the successful de-convolution of the isotopic fine structure at $\mathrm{m} / \mathrm{z} 845$, which was resolved into two close peaks with over 200000 resolution achieved. One peak with $\mathrm{m} / \mathrm{z}$ 845.51475 was assigned as the ${ }^{15} \mathrm{~N}$ peak for labeled meridamycin $\left(\mathrm{C}_{45} \mathrm{H}_{75}{ }^{15} \mathrm{NO}_{12} \mathrm{Na}^{+}\right.$, calcd $\mathrm{m} / z$ 845.51519, $\left.\Delta=-0.44 \mathrm{mmu}\right)$, and another peak with $\mathrm{m} / z 845.52147$ was assigned as the ${ }^{13} \mathrm{C}$ peak for unlabeled meridamycin $\left(\mathrm{C}_{44}{ }^{13} \mathrm{CH}_{75} \mathrm{NO}_{12} \mathrm{Na}^{+}\right.$, calcd $\mathrm{m} / z$ 845.52151, $\Delta=-0.04 \mathrm{mmu}$ ) (Figure 2a). Similar resolution was also achieved for the sample prepared from $\mathrm{L}_{-}\left[\varepsilon^{-}{ }^{15} \mathrm{~N}\right]$-lysine feeding (Figure $2 \mathrm{~b}$ ).

The measured abundances for the ${ }^{15} \mathrm{~N}$ and ${ }^{13} \mathrm{C}$ isotopic peaks relative to that for the monoisotopic peak of unlabeled meridamycin are listed in Table 2 . The ${ }^{15} \mathrm{~N}$-labeled contents were calculated based on the formula $\left(A_{1}-0.0037 \times A_{0}\right) /\left(A_{0}+A_{1}-0.0037 \times A_{0}\right)$, where $A_{1}$

Table 1 Incorporation of L-[3,3,4,4,5,5,6,6-D $]$-lysine into meridamycin

\begin{tabular}{lcc}
\hline Sample & Observed ions & Area ratio \\
\hline No feeding & $806.7,820.7$ & $1: 02$ \\
Feeding with lysine $\left(\mathrm{d}_{8}\right) 2 \mathrm{~mm}$ & $806.7,820.7,828.7$ & $1: 0.8: 0.7$ \\
Feeding with lysine $\left(\mathrm{d}_{8}\right), 4 \mathrm{~mm}$ & $806.7,820.7,828.7$ & $1: 0.5: 1.1$
\end{tabular}

Mass ions: meridamycin: 820.7; normeridamycin: 806.7; deuterated meridamycin[ $\left.D_{8}\right]$ : 828.7. 

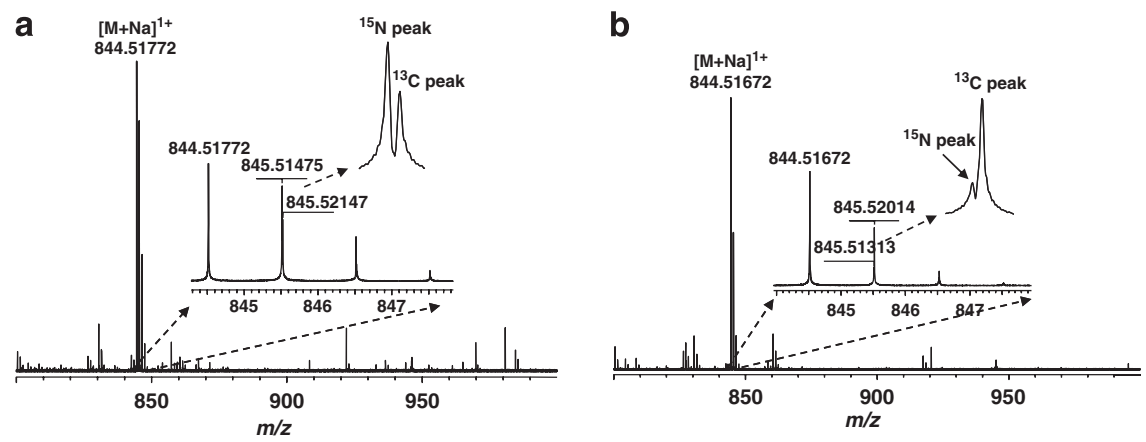

Figure 2 Positive mode nanoelectrospray Fourier transform mass spectrometry (FTMS) mass spectrum of meridamycin detected in Streptomyces sp. NRRL30748 fermentations. (a) Fermentation fed with $L-\left[\alpha^{-15} \mathrm{~N}\right]-$ lysine; (b) fermentation fed with $L-\left[\varepsilon^{-15} \mathrm{~N}\right]-$ lysine.

Table 2 Labeling contents of the ${ }^{15} \mathrm{~N}$-labeled meridamycin derived from the $[\mathrm{M}+\mathrm{Na}]^{+}$molecular ion by FTMS

\begin{tabular}{|c|c|c|c|c|c|c|c|}
\hline \multicolumn{2}{|l|}{ Feeding } & \multicolumn{3}{|c|}{$L-[\alpha-15 N]-L y s$} & \multicolumn{3}{|c|}{ L- $-[\varepsilon-15 N]-L y s$} \\
\hline Product & $\begin{array}{c}\text { Predicted } \\
\mathrm{m} / \mathrm{z}\end{array}$ & $\begin{array}{c}\text { Experimental } \\
\mathrm{m} / \mathrm{z}^{\mathrm{a}}\end{array}$ & $\begin{array}{c}\text { Relative } \\
\text { abundance (\%) }\end{array}$ & $\begin{array}{c}\text { Portion } \\
(\%)^{c}\end{array}$ & $\begin{array}{c}\text { Experimental } \\
\mathrm{m} / \mathrm{z}\end{array}$ & $\begin{array}{c}\text { Relative } \\
\text { abundance (\%) }\end{array}$ & $\begin{array}{c}\text { Portion } \\
(\%)\end{array}$ \\
\hline Unlabeled $\left(\mathrm{C}_{45} \mathrm{H}_{75} \mathrm{NO}_{12} \mathrm{Na}^{+}\right)$ & 844.5182 & $844.51772(-0.43)$ & 100 & 57 & $844.51672(-1.43)$ & 100 & 86 \\
\hline${ }^{15} \mathrm{~N}$-labeled $\left(\mathrm{C}_{45} \mathrm{H}_{75}{ }^{15} \mathrm{NO}_{12} \mathrm{Na}^{+}\right)$ & 845.5152 & $845.51475(-0.44)$ & 77 & 43 & $845.51313(-2.06)$ & 16 & 14 \\
\hline${ }^{13} \mathrm{C}$ isotopic $\left(\mathrm{C}_{44}{ }^{13} \mathrm{CH}_{75} \mathrm{NO}_{12} \mathrm{Na}^{+}\right)$ & 845.5215 & $845.52147(-0.04)$ & 52 & & $845.52014(-1.37)$ & 51 & \\
\hline
\end{tabular}

Abbreviation: FTMS, Fourier transform mass spectrometry.

aErrors (mDa) in parentheses calculated as experimental value-predicted value.

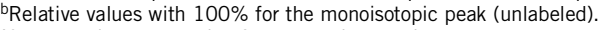

'See Experimental section for calculation details.

represents the measured relative abundance for the resolved ${ }^{15} \mathrm{~N}$ labeled meridamycin peak $\left([\mathrm{M}+\mathrm{H}]^{+}\right.$, predicted $\mathrm{m} / \mathrm{z} 823.53324$ or $[\mathrm{M}+\mathrm{Na}]^{+}$, predicted $\left.\mathrm{m} / z 845.51519\right)$, and $A_{0}$ represents the measured relatives abundance for the monoisotopic peak of unlabeled meridamycin $\left([\mathrm{M}+\mathrm{H}]^{+}\right.$, predicted $m / z 822.53620$ or $[\mathrm{M}+\mathrm{Na}]^{+}$, predicted $m / z$ $844.51815)$. The coefficient 0.0037 is the calculated ratio of the peak heights for the naturally occurring ${ }^{15} \mathrm{~N}$ isotopic peak over the monoisotopic peak of unlabeled meridamycin, using Bruker Xmass software (version 5.02; Bruker Corporation). For the sample generated from $\mathrm{L}-\left[\alpha_{-}{ }^{15} \mathrm{~N}\right]$-lysine feeding, the measured relative peak abundances of the unlabeled meridamycin and the mono- ${ }^{15} \mathrm{~N}$-labeled species for the sodium adduct molecular ion $\left([\mathrm{M}+\mathrm{Na}]^{+}\right)$are $100 \%\left(A_{0}\right)$ and $77 \%$ $\left(A_{1}\right)$, respectively. Therefore, the proportion of meridamycin with mono- ${ }^{15} \mathrm{~N}$ labeling was calculated as $\sim 43 \%$ using the aforementioned formula, with the remaining proportion of $\sim 57 \%$ as the unlabeled product. In contrast, when the culture was fed $\mathrm{L}_{-}\left[\varepsilon^{-}{ }^{15} \mathrm{~N}\right]-$ lysine, the proportions of ${ }^{15} \mathrm{~N}$-labeled meridamycin were calculated to be $14 \%$. In either condition, the peak abundance of the ${ }^{13} \mathrm{C}$ isotope of the unlabeled species is $\sim 52 \%$, which was in good agreement with the calculated value of 0.5173 , indicating an acceptable measurement deviation for the monoisotopic and the ${ }^{15} \mathrm{~N}$ peak abundances.

Since the calculated relative abundance of the naturally occurring ${ }^{15} \mathrm{~N}$ isotope of meridamycin is just $0.37 \%$ of the monoisotope, the fact that significantly higher enrichment of ${ }^{15} \mathrm{~N}$ in meridamycin, $\sim 43$ and $\sim 14 \%$, respectively, was detected when either $\mathrm{L}-\left[\alpha^{-15} \mathrm{~N}\right]$-lysine or $\mathrm{L}-\left[\varepsilon^{-15} \mathrm{~N}\right]$-lysine was fed into the growth medium strongly suggests that the enrichments by both precursors were specific. This result clearly indicates that both the $\alpha$-amino nitrogen and the $\varepsilon$-amino nitrogen in L-lysine can be incorporated into pipecolate, though at different ratios. Therefore, both the 'A' and 'B' pathways in Figure 1 must coexist in Streptomyces sp. NRRL30748 and are employed in the conversion of lysine into pipecolate, which is then incorporated into meridamycin. This observation is in sharp contrast with the results of the isotopic-labeling studies conducted for FK520 and rapamycin, in which specific enrichment could only be detected with $\mathrm{L}-\left[\varepsilon^{-}{ }^{15} \mathrm{~N}\right]$ lysine feeding, in agreement with the loss of $\alpha$-amine in the cyclodeamination reaction catalyzed by lysine cyclodeaminase, FkbL or RapL (H Jiang, unpublished data).

\section{Cloning and characterization of genes involved in pipecolate biosynthesis}

Since more specific ${ }^{15} \mathrm{~N}$ enrichment in meridamycin was detected with $\mathrm{L}-\left[\alpha_{-}{ }^{15} \mathrm{~N}\right]$-lysine feeding compared with $\mathrm{L}-\left[\varepsilon^{-}{ }^{15} \mathrm{~N}\right]$-lysine feeding, we assume that path ' $\mathrm{B}$ ' would be more efficiently utilized by this microorganism to convert lysine to pipecolate. Therefore, disruption of this pathway might result in a significant loss of meridamycin production, and increased production of normeridamycin might be achieved by feeding the mutant strain with proline. We thus sought to identify genetic loci involved in this pathway.

The $\varepsilon$-deamination of L-lysine to form P6C can be catalyzed by a lysine-6-aminotransferase (for example, in the $\beta$-lactam antibiotic producing actinomycetes Streptomyces clavuligerus ${ }^{19}$ and Nocardia lactamdurans, ${ }^{20}$ or gram-negative bacteria Flavobacterium lutescence ${ }^{21}$ ) or by an L-lysine-6-dehydrogenase as in Agrobacterium tumefaciens. ${ }^{22}$ The enzyme dedicated to the second step in this pathway, the reduction of $\mathrm{P} 6 \mathrm{C}$ to form pipecolate, has not been identified in bacteria. However, E. coli $\mathrm{P} 5 \mathrm{C}$ reductase, which catalyzes the terminal step in proline biosynthesis, was found to be able to efficiently catalyze the conversion of $\mathrm{P} 6 \mathrm{C}$ into pipecolate. ${ }^{23}$ It was possible that in microorganisms that utilize the $\mathrm{P} 6 \mathrm{C}$ pathway to produce pipecolate, 
Figure 3 Amino-acid sequence alignment of the partial protein encoded by proC gene cloned from Streptomyces sp. NRRL30748 with the pyrroline-5carboxylate (P5C) reductase encoded by the proC gene from S. coelicolor.

this universally conserved $\mathrm{P} 5 \mathrm{C}$ reductase might be responsible for the reduction of $\mathrm{P} 6 \mathrm{C}$ to L-pipecolic acid. Therefore, inactivation of this gene might be sufficient to block the majority of pipecolate production in Streptomyces sp. NRRL30748.

Degenerate PCR primers have been designed based on the conserved amino-acid sequences of several identified bacterial P5C reductases and were used to clone genes encoding this enzyme from Streptomyces sp. NRRL30748 by PCR. A DNA fragment of $\sim 500 \mathrm{bp}$ was amplified and shown to share over $90 \%$ sequence identity with the internal portion of the proC gene that encode the $\mathrm{P} 5 \mathrm{C}$ reductase from S. coelicolor. DNA sequence of the full-length proC gene was obtained by cosmid screening and sequencing, and the deduced amino-acid sequence encoded by this gene showed over $80 \%$ identity to the P5C reductase from $S$. coelicolor (Figure 3).

To test whether this proC gene was involved in the production of pipecolic acid, an internal portion of this gene was replaced with the apramycin resistance gene and then introduced into Streptomyces sp. NRRL30748 to replace the native allele via a double crossover. The wild-type strain and three individually isolated proC disruption mutants were fermented in the presence of unlabeled L-lysine, $L-[\alpha-$ $\left.{ }^{15} \mathrm{~N}\right]$-lysine or $\mathrm{L}-\left[\varepsilon^{-15} \mathrm{~N}\right]$-lysine. However, there was no significant difference in total meridamycin production between each strain when the same type of L-lysine precursor was added to the production medium (Figure $4 \mathrm{a}$ ). Neither did it affect the production of normeridamycin (data not shown). Furthermore, this gene disruption did not affect the incorporation of either $\left[\alpha^{-15} \mathrm{~N}\right]$-labeled or $\left[\varepsilon^{-15} \mathrm{~N}\right]$-labeled lysine into meridamycin, as there was no significant difference in the relative contents of ${ }^{15} \mathrm{~N}$-labeled meridamycin generated by the wildtype strain and by the proC mutant when either precursor was added (Figure 4b). Taken together, these results suggest the protein encoded by the proC gene is not rate limiting for the biosynthesis of the pipecolate moiety of meridamycin in Streptomyces sp. NRRL30748. It is possible that Streptomyces sp. NRRL30748 not only employs both P2C and P6C pathways for pipecolate synthesis, but also has multiple routes in each pathway. If this is true, disruption of one route could be compensated by the upregulation of an alternative path and therefore would not affect the overall supply of pipecolate. Interestingly, a similar phenomenon was also observed in S. hygroscopicous: pipecolate-containing rapamycin was still produced in significant amount after disruption of the rapL gene, suggesting the existence of an alternative route for lysine $\alpha$-amine elimination in addition to the well-established RapL pathway (H Jiang, unpublished data).

Understanding the biosynthetic pathways leading to the production of novel natural products are of great interest to drug discovery, since

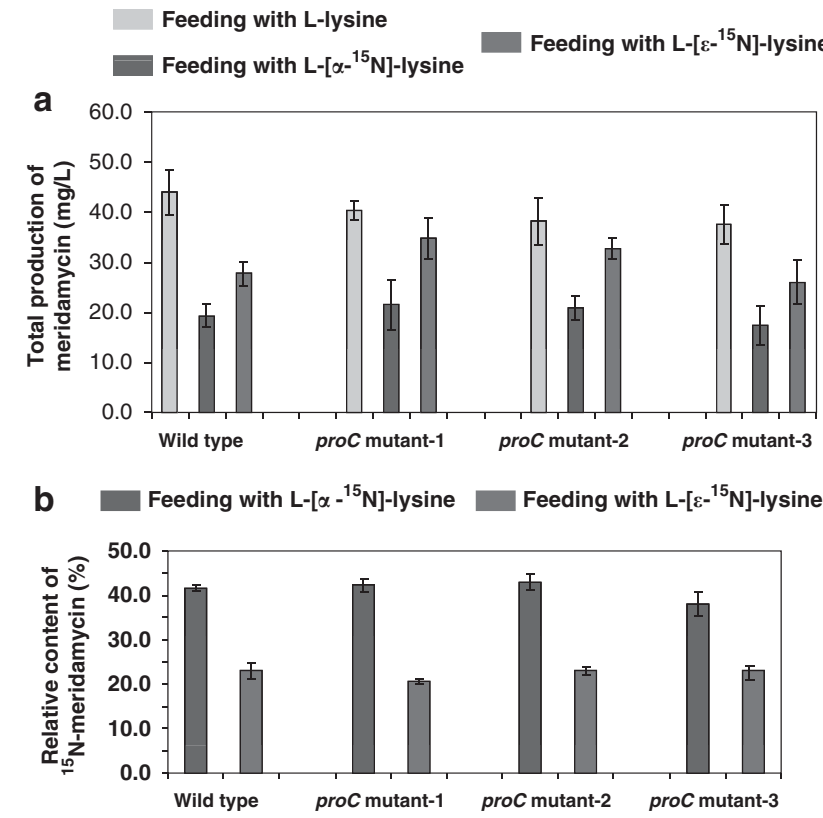

Figure 4 Comparison of total meridamycin production (a) and relative enrichment of ${ }^{15} \mathrm{~N}$-labeled meridamycin (b) by Streptomyces $\mathrm{sp}$. NRRL30748 and proC::apr mutant in fermentations fed with unlabeled L-lysine, L-[ $\left.\alpha_{-}^{-15} \mathrm{~N}\right]$-lysine or $\mathrm{L}_{-}\left[\varepsilon^{-}{ }^{15} \mathrm{~N}\right]$-lysine (average data of triplicates).

such knowledge can be used to improve yields of rare natural products and to facilitate the generation of novel analogs for structure-activity relationship study and lead optimization. Feeding studies using stable isotopic-labeled precursors is an effective way to elucidate the biogenesis of key functional components of medically important natural products. We have reported here the incorporation of L-lysine individually labeled with ${ }^{15} \mathrm{~N}$ at the $\alpha$ or $\varepsilon$ position into meridamycin. Reliable interpretation of the chemistry of biosynthetic processes was facilitated by FTMS, which had revealed the isotopic fine structure of ${ }^{15} \mathrm{~N}$-labeled meridamycin based on ultra-high resolution and enabled the unambiguous identification of the resolved ${ }^{15} \mathrm{~N}$ and ${ }^{13} \mathrm{C}$ peaks with p.p.m. mass measurement accuracy. The analysis results clearly demonstrated the efficient incorporation of both $\alpha-{ }^{15} \mathrm{~N}$ - and $\varepsilon^{-}{ }^{15} \mathrm{~N}$ labeled amines of L-lysine into the pipecolate moiety of meridamycin, suggesting two distinguishable pathways, each with the loss of a specific amino group of lysine, are utilized for pipecolate biosynthesis in Streptomyces sp. NRRL30748. To the best of our knowledge, this is 
the first report of the coexistence of both P2C and P6C pathways for pipecolic acid biosynthesis in a single microorganism. Although efforts to identify the major gene product responsible for the production of pipecolate were not fruitful, our studies have revealed the diversity and complexity of the pathways leading to the generation of this important biosynthetic precursor of meridamycin in Streptomyces sp. NRRL30748, and strongly suggest alternative genetic engineering strategies may be more effective at generating mutant strain capable of incorporating amino acids other than pipecolate into meridamycin (for example, modification of the pipecolate-incorporating non-ribosomal peptide synthetase MerP).

\section{CONFLICT OF INTEREST}

The authors declare no conflict of interest.

1 Summers, M. Y., Leighton, M., Liu, D., Pong, K. \& Graziani, E. I. 3-Normeridamycin: a potent non-immunosuppressive immunophilin ligand is neuroprotective in dopaminergic neurons. J. Antibiot. (Tokyo) 59, 184-189 (2006).

2 Wilson, K. P. et al. Comparative X-ray structures of the major binding protein for the immunosuppressant FK506 (tacrolimus) in unliganded form and in complex with FK506 and rapamycin. Acta. Crystallogr. D Biol. Crystallogr. 51, 511-521 (1995).

3 Broquist, H. P. Lysine-pipecolic acid metabolic relationships in microbes and mammals. Annu. Rev. Nutr. 11, 435-448 (1991).

$4 \mathrm{He}, \mathrm{M}$. Pipecolic acid in microbes: biosynthetic routes and enzymes. J. Ind. Microbiol. Biotechnol. 33, 401-407 (2006).

5 Khaw, L. E., Bohm, G. A., Metcalfe, S., Staunton, J. \& Leadlay, P. F. Mutational biosynthesis of novel rapamycins by a strain of Streptomyces hygroscopicus NRRL 5491 disrupted in rapL, encoding a putative lysine cyclodeaminase. J. Bacteriol. 180, 809-814 (1998).

6 Gatto, G. J. Jr., Boyne, M. T. II, Kelleher, N. L. \& Walsh, C. T. Biosynthesis of pipecolic acid by RapL, a lysine cyclodeaminase encoded in the rapamycin gene cluster. J. Am. Chem. Soc. 128, 3838-3847 (2006).

7 Schwecke, T. et al. The biosynthetic gene cluster for the polyketide immunosuppressant rapamycin. Proc. Natl Acad. Sci. USA 92, 7839-7843 (1995).
8 Motamedi, H. \& Shafiee, A. The biosynthetic gene cluster for the macrolactone ring of the immunosuppressant FK506. Eur. J. Biochem. 256, 528-534 (1998).

9 Wu, K., Chung, L., Revill, W. P., Katz, L. \& Reeves, C. D. The FK520 gene cluster of Streptomyces hygroscopicus var. ascomyceticus (ATCC 14891) contains genes for biosynthesis of unusual polyketide extender units. Gene 251, 81-90 (2000).

10 Namwat, W. Kamioka, Y. Kinoshita, H. Yamada, Y. \& Nihira, T. Characterization of virginiamycin S biosynthetic genes from Streptomyces virginiae. Gene 286, 283-290 (2002).

11 Sandmann, A., Sasse, F. \& Muller, R. Identification and analysis of the core biosynthetic machinery of tubulysin, a potent cytotoxin with potential anticancer activity. Chem. Biol. 11, 1071-1079 (2004).

12 Muller, C. et al. Sequencing and analysis of the biosynthetic gene cluster of the lipopeptide antibiotic Friulimicin in Actinoplanes friuliensis. Antimicrob. Agents Chemother. 51, 1028-1037 (2007).

$13 \mathrm{He}$, M., Haltli, B., Summers, M., Feng, X. \& Hucul, J. Isolation and characterization of meridamycin biosynthetic gene cluster from Streptomyces sp. NRRL 30748. Gene 377, 109-118 (2006).

14 Kuo, M. S. et al. Biosynthesis of the pipecolate moiety of marcfortine A. J. Am. Chem. Soc. 121, 1763-1767 (1999).

15 Marshall, A. G., Hendrickson, C. L. \& Jackson, G. S. Fourier transform ion cyclotron resonance mass spectrometry: a primer. Mass Spectrom. Rev. 17, 1-35 (1998).

16 Feng, X. D. et al. Probing natural product biosynthetic pathways using Fourier transform ion cyclotron resonance mass spectrometry. Bioorg. Med. Chem. 17, 2154-2161 (2009).

17 Bentley, S. D. et al. Complete genome sequence of the model actinomycete Streptomyces coelicolor A3(2). Nature 417, 141-147 (2002).

$18 \mathrm{lkeda}, \mathrm{H}$. et al. Complete genome sequence and comparative analysis of the industrial microorganism Streptomyces avermitilis. Nat. Biotechnol. 21, 526-531 (2003).

19 Madduri, K. et al. Lysine catabolism and alpha-aminoadipate synthesis in Streptomyces clavuligerus. Appl. Microbiol. Biotechnol. 35, 358-363 (1991).

20 Coque, J. J. R., Liras, P., Laiz, L. \& Martin, J. F. A gene encoding lysine 6aminotransferase, which forms the beta-lactam precursor alpha-aminoadipic acid, is located in the cluster of cephamycin biosynthetic genes in Nocardia lactamdurans. J. Bacteriol. 173, 6258-6264 (1991).

21 Fujii, T., Narita, T., Agematu, H., Agata, N. \& Isshiki, K. Characterization of L-lysine 6aminotransferase and its structural gene from Flavobacterium lutescens IF03084. J. Biochem. 128, 391-397 (2000).

22 Misono, H., Hashimoto, H., Uehigashi, H., Nagata, S. \& Nagasaki, S. Properties of L-lysine Epsilon-dehydrogenase from Agrobacterium tumefaciens. J. Biochem. 105, 1002-1008 (1989).

23 Fujii, T., Aritoku, Y., Agematu, H. \& Tsunekawa, H. Increase in the rate of L-pipecolic acid production using lat-expressing Escherichia coli by lysP and yeiE amplification. Biosci. Biotechnol. Biochem. 66, 1981-1984 (2002). 